\title{
A(s) história(s) contada(s) no livro didático hoje: entre o nacional e o mundial
} History in today's textbooks: between national and global

\author{
Helenice Ap. Rocha*
}

Flavia Eloisa Caimi**

\section{Resumo}

O foco do estudo é a composição da narrativa nos Livros Didáticos de História (LDH) quanto à organização curricular assumida nas últimas décadas, que ora se manifesta de forma separada, ora de forma integrada entre a história do Brasil e a história mundial. No artigo, além de apresentar breve histórico da movimentação de tais narrativas na produção didática brasileira, empreendemos a análise de modo a evidenciar algumas das estratégias de organização curricular e de construção textual que os livros utilizam para estabelecer relações entre a história nacional e a mundial em sua estrutura narrativa. Os resultados preliminares do estudo apontam que os LDH procuram dar conta de uma tradição historiográfica e curricular predominantemente cronológico-linear de organização dos conteúdos de História, mas buscam estratégias para inovar no sentido de estabelecer articulações na abordagem nacional-mundial e de superar dissociações entre instâncias espaciais e temporais.

Palavras-chave: livro didático; narrativa; História Mundial.

\section{Abstract}

This study focus at the narrative composition in History textbooks about the curricular organization assumed at the last decades, which manifests sometimes in a separate way and sometimes integrated between Brazil History and world History. The article, besides the brief description of the changes in those narratives at the didactic Brazilian production, shows the analysis as a way to evidence some of the curricular organizational strategies and textual construction the books uses to establish resemblance between national and global history at its narrative structure. The preliminary results of the study indicates that the History textbooks pursuit the consideration of a historiographical and curricular tradition, which is predominantly chronologic-linear organization of the History contents, but look for strategies to innovate the sense of establish articulations at the national-worldwide approach and overcome dissociations between space and temporal instances.

Keywords: History textbook; narrative; World History.

\footnotetext{
* Universidade do Estado do Rio de Janeiro (Uerj). helarocha@gmail.com

** Universidade de Passo Fundo (UPF). caimiribeiro@via-rs.net
} 
Debates sobre a adequação e a primazia entre os conteúdos relativos à História do Brasil e à História Geral na organização curricular da disciplina na escola brasileira vieram ocorrendo desde o século XIX até o início deste século, provocados por diferentes preocupações. Desde a busca de afirmação da relevância de se iniciar os estudos pelo espaço e tempo mais próximo até o mais distante, embasada na natureza mais ou menos complexa do conhecimento histórico ou na necessidade de sua aproximação às condições cognitivas de aprendizagem dos alunos. Essas e outras preocupações habitaram as discussões de historiadores, outros intelectuais, professores e pesquisadores do ensino. ${ }^{1}$

Nesse cenário, os livros didáticos destinados ao ensino fundamental no Brasil até meados da década de 1980 eram publicados em coleções de quatro volumes, sendo os dois primeiros dedicados à história do Brasil ( $5^{\mathrm{a}}$ e $6^{\mathrm{a}}$ séries) e os dois últimos à história Geral ( $7^{\mathrm{a}}$ e $8^{\mathrm{a}}$ séries). Mesmo assim, era possível os professores e secretarias de Educação decidirem a ordem de tratamento dos conteúdos relativos a cada uma, já que funcionavam de forma independente. Ao final do século XX, foram disponibilizadas outras alternativas editoriais e curriculares, em um momento que favoreceu experiências de organização dos conteúdos diversas da anterior e que necessariamente mesclavam, de forma mais ou menos articulada, esses dois blocos de conhecimentos. Dentre elas, destacou-se a chamada "história integrada" como estratégia narrativa predominante nos dias de hoje.

Neste artigo, o propósito é identificar, num conjunto de coleções didáticas de História destinadas aos anos finais do ensino fundamental ( $6^{\circ}$ ao $9^{\circ}$ ano), a maneira como vem sendo elaborada e apresentada a narrativa integrada. Destacamos em nossa análise os tipos de relações estabelecidas entre os conteúdos relativos à história do Brasil e os de história mundial, no mesmo volume.

Para isso, na primeira seção do artigo apresentamos breve histórico sobre as denominações atribuídas ao que hoje ainda conhecemos como História Geral e as diversas articulações curriculares entre ela e a história do Brasil, e destacamos os livros didáticos como textos que conferem visibilidade às organizações curriculares em História e constituem, portanto, parte do seu código disciplinar. ${ }^{2}$ Ainda nessa seção, caracterizamos a história integrada como uma novidade dos livros didáticos de história no Brasil e analisamos sua repercussão sobre o conjunto de coleções que, gradativamente, passaram a se organizar dessa maneira e, consequentemente, sobre a organização curricular da disciplina nas escolas. A seguir, investigamos as relações estabelecidas entre uma e outra, tomando como unidade de análise o tema da Ditadura civil-militar no 
Brasil, com destaque para as estratégias de articulação entre os capítulos que tratam da história do Brasil e os que tratam da história mundial. O corpus examinado é constituído de 16 coleções de História aprovadas no PNLD/2011 e destinadas aos anos finais do ensino fundamental. ${ }^{3}$

\section{O LUGAR DE CADA NARRATIVA NA ORGANIZAÇÃO CURRICULAR DA HISTÓRIA ESCOLAR}

A passagem do século XIX para o XX foi um período, dentre outros, que orientou uma dupla definição: de uma parte, a especificação da disciplina História a ser ensinada nas escolas, que transitou naquele momento entre a História Universal e a História Geral; de outra parte, o lugar autônomo, ou não, reservado para a disciplina de História do Brasil na relação com essa outra história. Vejamos brevemente o percurso dessas duas escolhas, que se entrelaçam.

Acompanhando o debate entre intelectuais sobre o sentido da história, as narrativas da História Universal e da História Geral expressam as lutas para definição da história que deveria ser ensinada para se atingir os objetivos da formação do cidadão. Não é por acaso que, em dez livros escolares de História Geral utilizados no Colégio Pedro II entre 1838 e 1907, quatro possuíam denominações como "Compêndio Universal", "História da Civilização" e "História Geral". Os outros compêndios tratavam de partes dos conteúdos relativos a períodos dessa história, com destaque para a Idade Antiga e a Idade Média, ou seja, partes dessa História Geral. ${ }^{4}$

Isso se explica pelo fato de que a Cadeira de História e Geografia teve suas aulas e matéria organizadas de forma diferenciada ao longo do tempo no Colégio. ${ }^{5}$ Assim, por exemplo, em 1856 o Plano de Estudos do Colégio de Pedro II para o conjunto de 7 anos do colegial se iniciava com a História Moderna no terceiro ano, passava à História Moderna e História Pátria no quarto ano, a seguir eram ministradas aulas de Geografia e História Antiga e, no sexto ano, Geografia e História da Idade Média. Já em 1882, no quinto ano havia História Geral: Antiga e Média, no sexto ano História Geral: Moderna, e no sétimo ano História e Corografia do Brasil. Interessante observar que a partir de 1892 os períodos da história seriam sempre submetidos a um título englobante: História Universal. Assim, passou-se a ter em 1892, no quinto ano História Universal (H.U.): Civilização Antiga; no sexto ano, H.U.: Civilização nas Idades Média e Moderna, e no sétimo ano, História do Brasil e Corografia. 
Na virada para o século XX ocorreu uma alteração significativa nos Planos de Estudos do Colégio Pedro II. A história do Brasil, que desde 1849 conquistara cadeira própria e era ministrada com exclusividade em determinados anos escolares, perdeu essa autonomia e passou a fazer parte das aulas de História Universal. Para alguns, esse movimento foi compreendido positivamente, como parte da atribuição de pertencimento do Brasil à civilização ocidental. Para outros, evidenciou um recuo na sua legitimidade e importância, num momento em que a disciplina de História via suas aulas serem cedidas para outras cadeiras da área científica. ${ }^{6}$

Entre uma reforma do ensino e outra, a história do Brasil retornou ao currículo de forma autônoma anos depois. Entretanto, em 1931, com a Reforma de Francisco Campos, voltou a fazer parte da História da Civilização, com nova denominação e com novos sentidos atribuídos à antiga História Universal. ${ }^{7}$ Essa legislação foi se alterando em meio a intensos debates entre historiadores e demais intelectuais que, em sua maioria, estavam preocupados com o campo disciplinar e com a educação escolar. Discutia-se como possibilidade, então, a relevância da história do Brasil, conferindo-lhe centralidade e antecedência diante da História da Civilização, ou, também, a pertinência de incluir o Brasil em um rol de nações, no estudo cronológico da História da Civilização. Quanto à organização curricular, foco que nos interessa mais diretamente aqui, os conteúdos sofreram significativa influência francesa, especialmente pela obra Histoire de la Civilization, de Charles Seignobos, com perspectiva marcadamente ocidental. ${ }^{8}$ Essa influência foi relativizada, porém, tanto pela introdução de lições que tratam da Antiguidade Oriental, quanto pela abordagem da história do Brasil, entremeada à marcha da civilização ocidental.

A Reforma Gustavo Capanema de 1942, ${ }^{9}$ postulada no bojo do projeto nacionalista do Estado Novo, garantiu a posição da história do Brasil como disciplina autônoma na escola secundária. Passaram a existir de forma independente a História do Brasil e a História Geral. A primeira com o papel primordial de cultuar fatos políticos e biografias dos maiores vultos da história pátria. A segunda, com a denominação de História Geral, sugeria a busca de superação dos sentidos atribuídos até então à História Universal e à História da Civilização, bastante criticadas por seu caráter hierárquico no tratamento das experiências civilizacionais diversas, com uma pretensão universalizante.

Instituíram-se, a partir de então, as bases para a composição do chamado "currículo convencional da história", também conhecido como currículo seriado, pelo qual se estudava primeiramente a história do Brasil em sua organização tripartite (história colonial, imperial e republicana), em 2 anos escolares, 
seguida da História Geral, em sua conhecida organização quadripartite (história antiga, medieval, moderna e contemporânea), nas duas séries seguintes.

Não obstante o nosso corpus principal circunscrever-se às coleções didáticas de História apresentadas no PNLD 2011, debruçamo-nos brevemente sobre alguns livros didáticos das décadas de 1980 e 1990, no intuito de esboçar as características básicas do currículo seriado. Para tanto, tomamos como exemplo três coleções ${ }^{10}$ que tiveram ampla difusão nas escolas brasileiras dentre tantas outras que poderiam ilustrar tal proposta -, representativas de diferentes momentos (1984, 1992 e 1997), mas comungando da mesma estratégia narrativa, que é a de separar o estudo da História do Brasil e da História Geral em dois blocos distintos.

Quadro 1 - Síntese do programa curricular das coleções didáticas seriadas

\begin{tabular}{|c|c|c|c|}
\hline & Coleção de 1984 & Coleção de 1992 & Coleção de 1997 \\
\hline $\begin{array}{c}5^{\mathrm{a}} \\
\text { série }\end{array}$ & $\begin{array}{l}7 \text { unidades } \\
\text { Estuda desde } O \text { Brasil } \\
\text { dos índios até O fim do } \\
\text { período colonial. }\end{array}$ & $\begin{array}{l}9 \text { unidades } \\
\text { Estuda desde Como o Brasil } \\
\text { nasceu, até as Rebeliões do } \\
\text { período regencial e as } \\
\text { características da Terra de } \\
\text { escravos. }\end{array}$ & $\begin{array}{l}14 \text { capítulos } \\
\text { Estuda desde O Brasil } \\
\text { no contexto da expansão } \\
\text { comercial europeia até } \\
\text { A vinda de D. João VIe } \\
\text { a emancipação política. }\end{array}$ \\
\hline $\begin{array}{c}6^{\mathbf{a}} \\
\text { série }\end{array}$ & $\begin{array}{l}7 \text { unidades } \\
\text { Estuda desde } A \\
\text { independência do } \\
\text { Brasil até a Semana de } \\
\text { Arte Moderna. }\end{array}$ & $\begin{array}{l}9 \text { unidades } \\
\text { Estuda desde O fim da } \\
\text { escravidão até Hoje, volta à } \\
\text { democracia. }\end{array}$ & $\begin{array}{l}15 \text { capítulos } \\
\text { Estuda desde o Brasil } \\
\text { independente até a } \\
\text { República dos militares } \\
\text { (1964-1985) }\end{array}$ \\
\hline $\begin{array}{c}7 \underline{a} \\
\text { série }\end{array}$ & $\begin{array}{l}5 \text { unidades } \\
\text { Estuda desde a Pré- } \\
\text { História até A Reforma } \\
\text { Católica ou Contra- } \\
\text { Reforma. }\end{array}$ & $\begin{array}{l}7 \text { unidades } \\
\text { Estuda desde as Origens, Big } \\
\text { Bang até } A \text { descoberta da } \\
\text { África pelos europeus. }\end{array}$ & $\begin{array}{l}22 \text { capítulos } \\
\text { Estuda desde } O \\
\text { surgimento da } \\
\text { civilização até A crise } \\
\text { do feudalismo. }\end{array}$ \\
\hline $\begin{array}{c}8^{\mathrm{a}} \\
\text { série }\end{array}$ & $\begin{array}{l}4 \text { unidades } \\
\text { Estuda desde } O \text { mundo } \\
\text { liberal, o absolutismo } \\
\text { até o Panorama } \\
\text { cultural do século XX. }\end{array}$ & $\begin{array}{l}11 \text { unidades } \\
\text { Estuda desde } O \\
\text { Renascimento até Hoje. }\end{array}$ & $\begin{array}{l}24 \text { capítulos } \\
\text { Estuda desde } O \text { mundo } \\
\text { não europeu até a } \\
\text { América Latina } \\
\text { contemporânea. }\end{array}$ \\
\hline
\end{tabular}

Fonte: Sistematização das autoras. 
Ainda que atribuam diferentes denominações aos assuntos das unidades e capítulos, verifica-se que as três coleções operam na mesma lógica, qual seja a de reservar as duas primeiras séries ao recorte nacional e as duas séries finais para o tratamento da História Geral. A abordagem dos conteúdos é essencialmente eurocêntrica, uma vez que a história do Brasil "nasce" em 1500. Uma das coleções parte do Brasil dos índios e justifica tal opção afirmando ser "óbvio que a história do Brasil tem início com a chegada dos portugueses, mas a pré-história brasileira não pode ser ignorada”, ou seja, mesmo quando parte da experiência indígena, o ponto de vista da narrativa é europeia. Ao longo dos dois primeiros volumes, a perspectiva daquela conhecida História da Civilização é que está a orientar a narrativa da história nacional.

Nos volumes finais, quando se trata propriamente da História Geral, denominação assumida pelas obras em clara oposição ao que é específico, no caso o nacional, a história do Brasil desaparece inteiramente da abordagem. É curioso ver, por exemplo, num capítulo intitulado América Latina Contemporânea (8 $8^{\text {a }}$ série), serem tratadas apenas as ditaduras da Guatemala (1954), do Chile (1973) e da Argentina (1976). Quanto à ditadura brasileira, a obra dispõe a observação de que este regime "você estuda no volume de história do Brasil". Remetendo-nos ao volume da $6^{a}$ série, verificamos que o tema é tratado no último capítulo, sob o título A República dos militares (1964-1985), sem aludir ao conturbado contexto político latino-americano sincrônico ao cenário brasileiro.

Essa organização curricular seriada perdurou de forma hegemônica até meados da década de 1980, ainda que tenha coexistido ao longo da década de 1990 com as propostas de história temática e de história integrada. O fim da ditadura civil-militar e a ausência de um currículo obrigatório de História em âmbito federal inspiraram mais enfaticamente a busca de alternativas curriculares e metodológicas que já havia anteriormente se iniciado e interrompido sob as imposições da ditadura. ${ }^{11}$

Desde meados do século XX, com a organização do ensino secundário, houve a criação de faculdades e universidades como a Universidade de São Paulo e a Faculdade Nacional de Filosofia. Na década de 1970, ainda sob a ditadura, organizam-se as primeiras pós-graduações e incrementam-se as interlocuções entre os pesquisadores, em âmbito nacional e internacional. A produção e os questionamentos resultantes desse contexto propiciaram o surgimento de propostas como a da história temática, cuja experiência foi 
encenada por diferentes coleções de livros didáticos, ainda sob a hegemonia dos livros com organização curricular convencional.

A formulação da história temática carrega a pretensão de romper com a perspectiva cronológico-linear ou, ao menos, de organizar os conteúdos com maior liberdade de estabelecer relações profícuas entre o passado e o tempo presente, extrapolando a sequência temporal quadripartite para a História Geral e tripartite para a História do Brasil. Nas décadas finais do século XX houve sistemas de ensino que adotaram a organização curricular temática da disciplina História e foram criadas coleções de livros didáticos que visaram atender tal proposta. ${ }^{12}$

As discussões contemporâneas sobre a história escolar ou, mais especificamente, sobre a sua organização curricular, precisam necessariamente levar em conta a presença do Programa Nacional do Livro Didático (PNLD) no cenário educacional brasileiro, cuja política foi amplamente redimensionada nos anos 1990, mas que tem sua origem muitas décadas antes. A política de materiais escolares inicia no Brasil em 1929, com a criação do Instituto Nacional do Livro (INL). De 1929 até 1985 houve várias alterações nos programas de materiais didáticos, de acordo com os diferentes contextos históricos do país, alternando-se períodos democráticos e épocas de ditaduras. Em 1985 é criado o Programa Nacional do Livro Didático, próximo ao formato hoje existente.

Com a publicação do documento intitulado Definição de Critérios para Avaliação dos Livros Didáticos, em 1994 (ver Brasil, 1994), desenharam-se os primeiros contornos da avaliação pedagógica atual. Desde então, a aquisição estatal de livros didáticos para a educação básica está condicionada à rigorosa avaliação de forma e conteúdo empreendida por professores da educação básica e da educação superior, todos experientes e especialistas no estudo da História como campo disciplinar acadêmico e escolar. Com base em editais de chamada às editoras, o PNLD vem estabelecendo parâmetros historiográficos, pedagógicos e editoriais para a organização de coleções de livros didáticos. Nesses parâmetros não se coloca restrição a nenhuma forma de organização curricular, o que torna o resultado da avaliação de livros de História do PNLD um termômetro em potencial das tendências de organização curricular disponíveis hoje no mercado editorial.

Por meio desse parâmetro é possível perceber que a história temática veio concorrendo com a história convencional (seriada) e, posteriormente, com a história integrada, uma nova alternativa de organização curricular do ensino de História que figura no cenário didático-editorial a partir da década 
de 1990. A primeira coleção com essas características localizada pelas autoras é a de autoria de José Jobson Arruda e se denomina História Integrada, oferecendo a seguinte explicação sobre essa nova forma de organização (ver Arruda, 1995, p.3):

Na coleção História Integrada, apresentamos a História Geral e a História do Brasil simultaneamente. Nosso objetivo é fazer com que você perceba que na História muitas coisas estão acontecendo ao mesmo tempo. E que, muitas vezes, fatos ocorridos do outro lado do mundo exercem uma grande influência na vida dos brasileiros.

Como obra lançada em 1995, em sua esteira vieram logo a seguir outras coleções, tanto que em 1998, já havia 8 coleções de história integrada aprovadas no PNLD, contra 3 de história convencional.

Neste artigo entende-se por história integrada a tentativa de estudar articuladamente e processualmente os conteúdos relativos à história mundial e à história do Brasil, tratando de diferentes sociedades e espacialidades num mesmo tempo cronológico. Assim, em tese, a história do Brasil deixa de ser trabalhada separadamente da história mundial, sendo incorporada na linha evolutiva ocidental de cunho eurocêntrico, sempre que houver pertinência. Os programas curriculares da História no ensino fundamental partem de uma espécie de introdução aos estudos históricos seguindo a perspectiva quadripartite-linear da História Geral, de modo que a história do Brasil (e da América, por vezes) comparece entremeada a ela.

Alicerçadas na concepção de que o Livro Didático de História é um dos textos visíveis do código disciplinar da História, de acordo com Cuesta Fernández (1997), buscamos averiguar como têm sido configuradas as propostas curriculares desse suporte cultural nos anos finais do ensino fundamental, tomando como fonte os Guias do PNLD História editados entre os anos de 1999 e 2014. Consoante aos propósitos do estudo, identificamos a movimentação das propostas segundo as categorias história convencional (seriada), história integrada e história temática.

Os dados sistematizados evidenciam o gradativo desaparecimento da abordagem curricular convencional/seriada, na qual os estudos de História Geral e do Brasil ocorriam separadamente nas séries finais do ensino fundamental, cedendo espaço crescente para a história integrada. 
Tabela 1 - Organização curricular anunciada nos Guias de Livros Didáticos PNLD História - Anos finais do ensino fundamental (1999-2014)

\begin{tabular}{c|c|c|c|c}
\hline Guia/Ano & $\begin{array}{c}\text { História } \\
\text { Convencional }\end{array}$ & $\begin{array}{c}\text { História } \\
\text { Integrada }\end{array}$ & $\begin{array}{c}\text { História } \\
\text { Temática }\end{array}$ & $\begin{array}{c}\text { Total de coleções } \\
\text { aprovadas }\end{array}$ \\
\hline $1999^{13}$ & 3 & 8 & - & 11 \\
2005 & 3 & 13 & 6 & 22 \\
2008 & 1 & 14 & 4 & 19 \\
2011 & - & 15 & 1 & 16 \\
2014 & - & 18 & 2 & 20 \\
\hline
\end{tabular}

Fonte: Guias do Livro didático de História do PNLD 1999, 2005, 2008, 2011, 2014. Sistematização das autoras.

Adentrando na composição das narrativas assumidas nas coleções de livros de História atualmente no Brasil, vemos que os conteúdos relativos à História Geral vieram se transformando nas últimas décadas, justificando a nova denominação de história mundial, adotada informalmente na referência a tais narrativas. ${ }^{14}$ Mesmo na parte que trata especificamente dessa escala mais ampla, outros países e continentes, para além da perspectiva eurocêntrica, adquiriram relevância na abordagem historiográfica. Ou seja, processos como o da atual globalização já entraram nos livros didáticos, sendo elaborados na perspectiva da história integrada.

Algumas coleções procuram contextualizar determinados processos para além das fronteiras nacionais, bem como estabelecer conexões inéditas entre histórias de países, seja por uma abordagem comparativa, seja estabelecendo relações causais entre os processos singulares de cada país. Fenômenos como a globalização são historicizados e apresentados em perspectiva integrada, não apenas como parte de uma história nacional. O esforço empreendido na composição dessa narrativa nos livros didáticos, nem sempre bem sucedido, atua no sentido de integrar os conteúdos da História em suas diversas espacialidades e temporalidades e, principalmente, de superar o viés ocidentalizante e eurocêntrico da narrativa histórica.

Tais mudanças ocorrem no momento em que se instala um debate historiográfico sobre a pertinência da escrita de uma história denominada mundial ou global, sob chaves de compreensão diversas daquelas da antiga História Universal e até da História Geral. Nascidas nas últimas décadas, tais propostas se originam da reflexão sobre o conjunto diversificado de processos em 
andamento no mundo contemporâneo, que afetam a todos, direta ou indiretamente. Estão em pauta as críticas à centralidade da Europa e à reiteração discursiva da periferia das outras civilizações, bem como a busca do estabelecimento de outras perspectivas para construir as narrativas sobre as histórias possíveis sobre o mundo e suas partes, sejam países, regiões ou temas mundiais. Assim, são propostas demandadas pelo tempo presente. ${ }^{15}$

Entendemos que os livros didáticos de História, quando reconfiguram a abordagem da História Geral em história mundial nas coleções constituídas sob a tipologia integrada e temática, apresentam uma novidade que não é uma resposta apenas a esse debate, mas uma perspectiva que dialoga ativamente com ele, interpelando-o. O uso do termo "novidade", neste estudo, não tem a conotação de adjetivo que busque qualificar a história integrada como uma alternativa melhor do que as outras, mas sim de apontar uma estratégia nova de organização curricular, que contém especificidades e atende a demandas diferentes das narrativas anteriores. É a essa singularidade que nos dedicaremos na sequência do artigo.

\section{História INTEGRADA: QUE RELAÇÕES ENTRE A HISTÓRIA DO BRASIL E A HISTÓRIA MUNDIAL?}

O que temos em um livro didático de História, uma narrativa ou narrativas que se comunicam? Entendemos que o texto principal do livro didático é uma narrativa histórica em sua modalidade escolar, ou seja, com fins didáticos. Mediante tal especificidade, o LDH opera com diferentes temas, alguns correlacionados e outros não, mas contém em cada capítulo ou tópico uma narrativa que se relaciona com outras narrativas ali presentes, com base em algumas estratégias. É a explicitação das correlações entre uma e outra narrativa que garante certa unidade na narrativa histórica escolar.

As coleções de história integrada sinalizam na direção de um estabelecimento maior ou menor de relações entre as histórias nacional e mundial. O objetivo desta seção é apresentar algumas das estratégias de tessitura, visando explicitar correlações entre as narrativas sobre a ditadura civil-militar brasilei$\mathrm{ra}$, as demais ditaduras latino-americanas, antecedentes ou fatores de mudanças na vida brasileira em sua inserção mundial. Para isso, destacamos uma estratégia relacionada à hierarquia das informações apresentada nos sumários dos volumes e a seguir apresentamos três pontos de ligação em que as narrativas sobre a ditadura evocam aspectos do contexto mundial. 
Trataremos então de elucidar o modo como os volumes relativos ao nono ano das 16 coleções aprovadas no PNLD/2011 relacionam essas duas histórias na sucessão de capítulos e unidades. A seguir, veremos como essas relações são estabelecidas dentro dos textos que tratam do tema da ditadura civil-militar no Brasil, com base em pontos de ligação.

\section{TÍtUlos COMO PORTAS DE ENTRADA DAS NARRATIVAS}

A hierarquização clara das informações no sumário se constitui como a primeira estratégia que uma parte das coleções estabelece para correlacionar a ditadura no Brasil e o contexto internacional. Os sumários das 16 coleções de História para o ensino fundamental se organizam conforme hierarquias de informação diferenciadas, entre unidades e capítulos. São 11 organizados em unidades e 5 em uma lista de capítulos organizados de forma linear. Além disso, nos sumários de todas as coleções é possível conhecer outros itens presentes nos livros como seções, dossiês, atividades e glossário, dentre outros. Aqui nos concentraremos nos títulos que conferem continuidade à narrativa, demarcando uma sequência de tópicos relativos aos conteúdos tratados.

O número de unidades e capítulos nessas coleções é variável. Nos livros do nono ano, há um mínimo de três e o máximo de oito unidades. A cada Unidade estão relacionados alguns capítulos, em média de três a quatro. Nas coleções que apresentam um rol de capítulos sem filiação a uma unidade, seu número varia entre 12 e 24 capítulos. Em ambos, pode haver ainda uma subdivisão, em tópicos relativos à sequência interna dos conteúdos.

A partir dessa descrição da forma de organização das obras mediante seus sumários, podemos afirmar que há unidades e capítulos que tratam apenas de uma história, nacional ou mundial, como neste exemplo, da Coleção 3:

Unidade IV: O Brasil entre duas ditaduras

Capítulo 12: Vargas, do afastamento ao retorno

Capítulo 13: De Juscelino a Jango

Capítulo 14: O Brasil em tempos de ditadura

- A deposição de Jango 
- O governo Castelo Branco

- O governo Costa e Silva

- O governo Geisel

- O governo Figueiredo

Vale dizer que mesmo em coleções como esta existe uma expectativa de integração dos conteúdos. A Unidade IV, O Brasil entre duas ditaduras, sucede a Unidade III: $O$ mundo bipartido, que veremos apresentar o conteúdo da Guerra Fria, um dos fatores sempre reiterados como relevantes para a crise do governo Jango e para a implantação da ditadura no Brasil.

Em outras coleções, existe uma alternância entre capítulos ou tópicos de uma ou outra história, não necessariamente relacionados. Das 16 coleções, oito são operacionalizadas nesse formato. Por exemplo, na Coleção 1, que se organiza em uma estrutura de 19 capítulos, ocorre a seguinte sequência que justapõe a história do Brasil e a história mundial: ${ }^{16}$

Capítulo 9: O mundo do pós-guerra

Capítulo 10: O Brasil do pós-guerra

Capítulo 11: O Golpe de 1964

Capítulo 12: A descolonização da Ásia e da África

Capítulo 13: A expansão e crise do socialismo

Capítulo 14: A reorganização e o apogeu do capitalismo

Capítulo 15: Brasil: os anos repressivos do regime militar

Capítulo 16: O final do governo militar no Brasil

Capítulo 17: A Nova República no Brasil

Em breve análise dos títulos, percebe-se que há uma alternância de temas nacionais e mundiais, em parte explicáveis pelo título, como é o caso dos capítulos 9 e 10, onde se identificam estratégias de inclusão - do Brasil no mundo - e de diferenciação - o Brasil é diferente do mundo - uma vez que o pósguerra no mundo é mais abrangente e antecede o Brasil no pós-guerra. De 
outra parte, as alternâncias são justificáveis pela temporalidade e correlações entre os eventos e processos, como nos capítulos 12 a 14, que tratam de temas mundiais implicados uns com os outros. E, finalmente, os capítulos 15 a 17 apresentam uma organização temporal dos eventos relativos à ditadura e a seu fim. Percebemos, assim, critérios diversos organizando a sucessão dos capítulos, e suas possíveis relações podem ser aludidas nessa sequência.

No conjunto das outras oito coleções, dentre as 16 que constituem o corpus em exame, existe uma organização mista. Ou seja, dentro de cada unidade, e às vezes no interior dos próprios capítulos, há itens que remetem a uma ou outra narrativa, num esforço mais consistente de integrar e não apenas justapor a abordagem das histórias nacional e mundial, ao menos, neste caso, no que diz respeito a uma parte do continente americano. Vejamos um exemplo extraído da Coleção 5:

\section{Unidade 4}

\section{Populismo, ditaduras militares e redemocratização no Brasil e em outros países latino-americanos e a contracultura}

Capítulo 12: O que significa viver sob o populismo no Brasil e em outros países da América Latina?

Capítulo 13: Ditaduras militares no Brasil e em outros países da América Latina: como era viver sob a repressão, a censura, a tortura e a luta armada?

Capítulo 14: Anos 1960-1970: nova cultura, novos hábitos de consumo e de comportamento

Capítulo 15: Redemocratização do Brasil e de outros países da América latina: $\mathrm{O}$ que significa ser democrático aqui?

A partir de seu título, percebemos que o conteúdo predominante nessa unidade é o da política brasileira em confronto com a latino-americana, sob o populismo e a ditadura. Os capítulos oferecem um paralelo entre a ditadura brasileira e a de outros países da América Latina e, ainda mais, sugerem que ocorriam mudanças naquele momento cujas repercussões se estendiam a um amplo conjunto de países. Algumas coleções estabelecem esse paralelismo entre o contexto mundial e a implantação de ditaduras na América Latina, dentre as quais a do Brasil. Dessa forma, mesmo que a partir de centros irradiadores 
como os Estados Unidos e a União Soviética em sua relação com países periféricos como os da América Latina, são estabelecidas conexões que demonstram o valor heurístico dessas aproximações.

Nessa mesma obra os temas tratados nos capítulos 12 a 14 da Coleção 1 são abordados na Unidade 3, com o título Guerra Fria, Descolonização da África e da Ásia e conflitos no Oriente Médio. Os três capítulos abordam apenas a história mundial. Entretanto, a unidade estabelece pelo título uma articulação prévia entre eles, evidenciando suas implicações mútuas.

Com base nesses exemplos e na leitura dos tópicos presentes no sumário das coleções integradas, percebe-se que a forma de organizar a sequência da narrativa é diversa. Entretanto, aquilo que se compreende na história escolar como um antecedente historicamente mais abrangente do que os marcos nacionais é apresentado em unidade ou capítulo anterior ou em tópicos dentro do próprio capítulo ou unidade, de forma a estabelecer conexões de sentido na narrativa mais ampla. Nota-se aqui uma diferença significativa em relação à proposta de história seriada anteriormente aludida, cujas conexões eram impossibilitadas na medida em que se estudava a ditadura civil-militar brasileira na $6^{a}$ série e as ditaduras latino-americanas apenas na $8^{\text {a }}$ série, sem nenhuma articulação entre os cenários.

No último exemplo citado anteriormente, relativo à Coleção 5, o título da Unidade IV anuncia os diferentes tópicos que serão tratados e a correlação entre as ditaduras militares latinas: Populismo, ditaduras militares e redemocratização no Brasil e em outros países latino-americanos e a contracultura, bem como aspectos da grande mudança cultural de repercussão mundial. Os capítulos desdobram o que o título da unidade anuncia, articulando eventos nacionais e regionais com o contexto mundial.

Do mesmo modo, a única coleção de história temática aprovada no PNLD 2011 - a Coleção 7 - na Unidade intitulada Autoritarismo e Democracia reúne, a partir do Capítulo 8, tópicos relativos a ambas as narrativas de forma articulada e seguindo a linearidade temporal: As duas guerras mundiais: nacionalismos e preconceitos; Era Vargas: retratos de uma nova ordem; Brasileiros, mostrem a sua cara e $O$ exercício democrático.

Diferentemente, a Coleção 13 se estrutura em módulos, sem títulos temáticos. No Módulo 5, o Capítulo 9 tem o título A Segunda Guerra e a queda de Vargas, estabelecendo dentro dele uma articulação espaço-temporal que permite relacionar eventos e processos simultâneos. O módulo seguinte, dedicado apenas à história do Brasil, trata da ditadura na sequência temporal dos 
eventos. O Capítulo 11 se intitula Brasil: da democracia à Ditadura, e seus tópicos são: De JK a Jango, Os anos de chumbo e A vez dos generais.

Observa-se que o livro de história integrada é construído utilizando diferentes estratégias de organização dos títulos do sumário de modo a já sinalizar ao leitor, ou não, onde haverá ligação entre as partes da narrativa como um todo integrado. Vejamos agora os pontos que, por dentro das narrativas, costuram as relações entre as histórias do Brasil e do mundo.

\section{A Guerra Fria e seus desdobramentos}

No corpo textual dos capítulos sobre a ditadura civil-militar, algumas coleções utilizam a estratégia de reiterar na narrativa sobre a história do Brasil informações já apresentadas anteriormente, relativas ao contexto mundial, constituindo-as como fatores explicativos. A relação entre a Guerra Fria e seus desdobramentos e o momento de crise da política brasileira, como o alinhamento de países do Brasil aos Estados Unidos, está presente em 13 coleções. Em apenas três delas encontramos referência a que tenha havido uma relação dos Estados Unidos com diversos países da América Latina. Um exemplo está na Coleção 5, na Unidade 4 e Capítulo 14, já mencionados, que entrelaça no mesmo texto as diferentes ditaduras latino-americanas, com proeminência para a brasileira:

Há vários estudiosos que dizem que os militares brasileiros teriam sido agentes de uma política internacional para a América Latina, liderada pelos Estados Unidos, a fim de garantir o total alinhamento do Brasil com os demais países capitalistas.

$\mathrm{Na}$ Coleção 4, além do capítulo relativo à Guerra Fria e da referência a sua influência no momento de crise institucional brasileira, menciona-se uma oferta de ajuda norte-americana ao golpe de Estado e a consequente subordinação do país: "O embaixador dos Estados Unidos ofereceu ajuda militar e financeira para o golpe ... O novo regime, uma ditadura militar, colocou o Brasil sob a tutela dos Estados Unidos".

Outra forma de estabelecer as relações entre uma e outra narrativa está no uso de adjetivos que caracterizam a filiação ideológica de sujeitos ou as representações existentes sobre ela. No momento da narrativa sobre a crise no governo João Goulart, em diversas coleções é apresentada a suspeita ou afirmações sobre a suposta tendência comunista do presidente, o que teria estabelecido uma desconfiança de setores da sociedade em relação a sua atuação 
no cargo presidencial, caso da Coleção 8, onde se lê que "Os setores conservadores consideravam as reformas pretendidas uma clara demonstração de que o presidente tinha ideias comunistas".

Ora, a adjetivação de comunista ao presidente Jango sem explicar o que é o comunismo se apoia em capítulos anteriores tais como a Guerra fria ou, até mesmo, nos que mencionam ideólogos do século XIX ou a Revolução Russa. A circulação de ideias entre o Brasil e outros países, nesse e em outros momentos, configura conexões intelectuais no nível internacional, se não, mundial.

\section{O Milagre Econômico na relação com a economia mundial}

O Milagre Econômico brasileiro é outro tópico abordado nas coleções que dialoga com fatores ou processo mundiais. Em continuidade à política de alianças dos Estados Unidos durante a Guerra Fria, muitos livros destacam que o Milagre Econômico foi intensamente financiado com capitais estrangeiros, sendo também fortemente abalado quando se instalou a crise do petróleo no Oriente Médio. A Coleção 8 exemplifica discursivamente a forma de construir essa relação:

Durante o governo do general Ernesto Geisel, entre 1974 e 1979, o Brasil enfrentou os efeitos da crise mundial do petróleo, que abalou profundamente a economia ... O "milagre econômico" dava mostras de sua fragilidade ... Em meio à crise, o governo alterou a tradicional política externa de alinhamento com os Estados Unidos...

Nas coleções que não destinam capítulos anteriores a essa crise e suas repercussões pelo mundo, tais observações aparecem no próprio capítulo relativo à ditadura brasileira, como uma menção. Temos assim que outra estratégia para estabelecer correlações está na abordagem desses tópicos como fatores ou características no desenvolvimento da própria narrativa sobre a ditadura, que deflagram ou propiciam a eclosão de mudanças significativas no país. Tal estratégia contribui para construir as explicações especialmente sobre os antecedentes e os desfechos dos acontecimentos.

\section{As transformações globais na cultura}

Algumas coleções mencionam, em tópico específico ou no desenvolvimento do texto, manifestações culturais no campo das artes em geral, bem 
como no âmbito dos costumes, que abalaram as décadas concomitantes ao desenrolar da ditadura civil-militar brasileira. A Coleção 5, no Capítulo 14, intitulado Anos 1960-1970: nova cultura, novos hábitos de consumo e de comportamento, trata das mudanças ocorridas nas formas de viver das sociedades a partir da grande industrialização e consequente criação de mercados de consumo para seus produtos, além de apresentar as mudanças nos costumes e padrões sociais relativamente à mulher e a outros segmentos minoritários. Também registra mudanças promovidas pelos movimentos jovens de contracultura. O livro enfatiza que essas transformações ocorriam em diversas partes do mundo, evidenciando as conexões propiciadas pela intensificação dos meios de comunicação e da expansão planetária de produtos culturais como a música.

Na maior parte das obras não há destaque para esse conjunto de mudanças, havendo o registro, em algumas delas, sobre movimentos culturais no Brasil, como a música de protesto, especialmente o rock e a Tropicália. Entretanto, a ênfase do tratamento aponta-os como manifestações de resistência, de forma descolada das grandes mudanças em curso em outros países.

Esses três pontos se referem a ligações entre uma e outra narrativa relativamente ao contexto político, econômico e cultural, com predominância dos dois primeiros. As relações podem ser organizadas como aspectos distintos. Um primeiro aspecto é o da importância às relações internacionais com blocos hegemônicos que dão a direção ao Brasil naquele momento impondo-lhe alianças, observado em relação à Guerra Fria e ao financiamento da economia nacional. Um segundo aspecto é o da permeabilidade dos diferentes países a crises internacionais que desequilibram situações estabelecidas, como é o caso da crise mundial do petróleo. Não existe um planejamento como no primeiro caso, e, sim, a crise se desencadeia, irradiando-se por diferentes países do mundo. Um último aspecto, secundarizado, está no plano dos efeitos e não dos fatores. A mudança cultural é apresentada como resultado da economia e da política, talvez por isso sua menor importância, já que é menos uma narrativa e mais uma descrição das mudanças no âmbito da expressão artística e dos costumes. Talvez, na tensa interlocução da modalidade escolar da narrativa histórica com o conhecimento de referência, a cultura ainda seja percebida como um aspecto separado da vida social, ou seu reflexo.

Koselleck dedicou-se a estudar a maneira, explícita ou implícita, como as experiências temporais manifestam-se na linguagem. Esse autor nos oferece uma reflexão sobre o tempo histórico que contribui para pensarmos a 
complexidade do que está em jogo nessas correlações, a partir da diferenciação entre estrutura e evento (Koselleck, 2006, p.136). Ele afirma:

Sem desejar avaliar aqui a relação de tais estruturas, podemos dizer que todas têm em comum o fato de suas constantes temporais ultrapassarem o campo de experiência cronologicamente registrável dos indivíduos envolvidos em um evento. Os eventos são provocados ou sofridos por determinados sujeitos, mas as estruturas permanecem supraindividuais e intersubjetivas. Elas não podem ser reduzidas a uma única pessoa e raramente a grupos precisamente determinados. Metodologicamente, elas requerem, por essa razão, determinações de caráter funcional. Com isso, as estruturas não se tornam grandezas extratemporais; ao contrário, elas adquirem frequentemente um caráter processual - que pode também se integrar às experiências dos eventos cotidianos.

Tal observação sobre a diferença entre evento e estrutura no sentido de a segunda extrapolar o campo de experiência cronologicamente registrável dos indivíduos talvez seja uma das chaves para pensar a compreensão sobre as inter-relações necessárias entre regiões e países no mundo contemporâneo

pelos alunos do ensino básico. Essas relações, em grande parte extrapolam não apenas o espaço nacional, mais concreto para esses alunos pela sua pretensa unidade. Elas extrapolam o tempo da experiência de vida desses alunos, ao tratar de contextos de maior duração. E envolvem países e regiões como sujeitos, além de correntes de pensamento que circulam produzindo mudanças, como o capitalismo e o comunismo, sempre citados nos capítulos relativos à ditadura brasileira. Assim, para além das inter-relações necessárias para conferir a integração desejada pelas coleções de livros de História, há que enfrentar a complexidade desse conhecimento que trata do próximo e do distante em relação.

\section{CONSIDERAÇÕES FINAIS}

Procuramos enumerar, ao longo do artigo, as diversas estratégias narrativas que consubstanciam as propostas curriculares da história escolar nas últimas décadas, no que se refere à primazia e exclusividade ou não para a história nacional ou mundial em suas narrativas. Num esforço final de síntese, poderíamos afirmar que a proposta de história integrada, atualmente hegemônica na produção didática brasileira, se define pela tentativa de abandonar a pretensão universalizante da história, entendida como a ambição de abarcar o 
estudo linear de todos os acontecimentos, de todas as sociedades e épocas, e que toma como fio condutor o mundo ocidental, mais especificamente a Europa.

Em que sentido essa mudança se coloca? Parece-nos que ela ocorre num cenário de transformações instituídas dentro daquilo que se convencionou denominar globalização ou mundialização, cujas repercussões impactam sobre os modos de produção do conhecimento. No caso do conhecimento histórico e, mais especificamente aqui, dos conhecimentos veiculados no livro didático que se pauta pela perspectiva da história integrada, encontramos narrativas diversas, em maioria com os mesmos marcos interpretativos, como se procurou demonstrar anteriormente. Concentrando-nos em aspectos gerais que caracterizam as narrativas da história integrada, elencamos, por exemplo, a preocupação com as histórias conectadas, ${ }^{17}$ pelas possibilidades que esta oferece de apreender a relação dialética entre os níveis global e regional, as particularidades e o modo de articulação das tendências mundiais, distinguindo o que é próprio, específico, singular de um sistema e o que se manifesta como tendência mais geral, sem tratá-lo como objeto isolado, separado daquilo que lhe dá significado no contexto.

Em tal perspectiva, pressupõe-se que não exista uma única história ou um ponto de vista único sobre ela. Há que se admitir que a história é feita de disjunções e conjunções em suas formas de temporalidade, as quais contêm interações, entrechoques, ocultamentos e imbricações, como ensina Hartog. Admitindo-se a inexistência do tempo único, também se reconhecem as múltiplas experiências do tempo e as diversas experiências humanas "em um mundo que nunca ignorou, em maior ou menor escala, trocas, interações e conflitos" (Hartog, 2003, p.176).

A decisão de se tratar o conhecimento histórico na perspectiva da história integrada - supondo-se que a abordagem seja bem sucedida e não apenas uma justaposição do nacional e do mundial - traz implicações para os processos escolares de ensinar e aprender História. Isso porque a compreensão sobre o Brasil e suas relações com o mundo pelos alunos do ensino básico exige um nível de pensamento histórico bem estruturado, pois mobiliza informações e correlações apresentadas pela narrativa apresentada pelos professores a seus alunos mas também presente nos livros de História, nosso objeto de estudo. E uma parte dessas correlações exige cada vez mais abstração, quando a narrativa se afasta do mundo empírico e do que está nele, e trabalha com categorias de pensamento como ideologias, relações de poder entre blocos de países e crises sistêmicas, como a do petróleo e, recentemente, a ambiental. 
Essa capacidade de abstração requerida diz respeito ao investimento no desenvolvimento de noções e funções cognitivas complexas, como temporalidade, simultaneidade, multicausalidade, mudança e permanência. Tais noções exigem habilidades de pensamento mais sofisticadas (que a memória, por exemplo), as quais são fundamentais para o desenvolvimento do pensamento histórico, uma vez que contribuem para extrapolar explicações personalistas ou simplistas e para avançar na compreensão das conexões e correlações entre as histórias humanas.

É nossa hipótese e aposta que o jogo de correlações necessárias entre o mais próximo e o mais distante, tanto no tempo quanto no espaço, na aula de história e nos materiais voltados a seu ensino, requisita investimentos que considerem essa complexidade quando se pretende elaborar uma narrativa integradora da história nacional e da história mundial. Tal investimento passa pela consideração de, por um lado, a rede de inter-relações possíveis entre espaços e tempos históricos. Em segundo lugar, pela consideração de que essa complexidade necessita se transformar em algo compreensível para alunos do ensino básico, com as características cognitivas e existenciais próprias a sua faixa etária e condições sociais.

Considerando-se tais complexidades, a formação histórica resultante poderá contribuir para o desenvolvimento de uma reflexão que extrapole a experiência de vida dos alunos do ensino básico. Uma alternativa para essa tarefa parte do suposto que a linguagem humana constitui conhecimento em suas formas de dizer, inclusive a narrativa histórica.

Há diferentes possibilidades, algumas delas vistas aqui, de estabelecer relações entre o nacional e o mundial. A mobilização deliberada de todos os recursos e linguagens disponíveis para a comunicação contemporânea que extrapolem a linearidade do texto escrito em um livro pode ser um caminho. Está posto o desafio para todos os que se dedicam a pensar o ensino e a aprendizagem da história.

\section{REFERÊNCIAS}

AQUINO, Rubim Santos Leão de. História das Sociedades: das comunidades primitivas às sociedades medievais. Rio de Janeiro: Ao Livro Técnico, 1980.

ARANHA, M. L. A. História da Educação. São Paulo, Moderna, 2002.

ARRUDA, José Jobson. História integrada: do fim do Antigo Regime à industrialização e ao imperialismo. São Paulo: Ática, 1995. 
BITTENCOURT, Circe. Livro Didático e Saber Escolar (1810-1910). Belo Horizonte: Autêntica, 2008.

BRASIL. Ministério da Educação e do Desporto. Definição de critérios para avaliação dos livros didáticos $-1^{\text {a }}$ a $4^{\text {a }}$ séries. Brasília: FAE, 1994.

CAIMI, Flávia Eloisa. Conversas e controvérsias: o ensino de história no Brasil (19801998). Passo Fundo: Ed. UPF, 2001.

CUESTA FERNÁNDEZ, Raimundo. Sociogénesis de una disciplina escolar: la Historia. Barcelona: Ed. Pomares-Corredor, 1997.

FARIA, Ricardo de Moura; MARQUES, Adhemar Martins. Nossa História, v.1-4. Belo Horizonte: Ed. Lê, 1984.

FONSECA, Selva Guimarães. Caminhos da história ensinada. Campinas, SP: Papirus, 1993.

GASPARELLO, Arlette M. Construtores de identidades: a pedagogia da nação nos livros didáticos da escola secundária brasileira. São Paulo: Iglu, 2004.

GRUZINSKI, Serge. O historiador, o macaco e a centaura: a "história cultural" no novo milênio. Revista Estudos Avançados, São Paulo, v.17, n.49, p.321-342, set.-dez. 2003.

HARTOG, François. Experiências do tempo: da História Universal à História Global? História, Histórias, Brasilia, v.1, n.1, p.164-179, 2013.

IGGERS, Georg G.; WANG, Q. Edward; MUKHERJEE, Supriya. A Global History of Modern Historiography. London: Pearson-Longman, 2008.

KOSELLECK, Reinhart. Futuro passado: contribuições à semântica dos tempos históricos. Rio de Janeiro: Ed. PUC-Rio, 2006.

MASLISH, Bruce. Comparing Global History to World History. The Journal of Interdisciplinary History, v.28, n.3, p.385-395, 1998.

MOCELLIN, Renato. Para compreender a História. São Paulo: Ed. do Brasil, 1997.

REZNIK, Luis. Tecendo o amanhã: a história do Brasil no Ensino Secundário: Programas e Livros didáticos. 1931 a 1945. Dissertação (Mestrado) - Departamento de História, ICHF, CEG, Universidade Federal Fluminense. Niterói, 1992.

SANTOS, Joel Rufino dos. História, Histórias. v.1-4. São Paulo: FTD, 1992.

WEINSTEIN, Barbara. História sem causa? A nova história cultural, a grande narrativa e o dilema pós-colonial. História, Franca, v.22, n.2, p.185-210, 2003.

\section{NOTAS}

${ }^{1} \mathrm{~A}$ respeito dos argumentos que problematizam as potencialidades e limites dessas alternativas curriculares, ver CAIMI, 2001.

${ }^{2}$ Termo cunhado por CUESTA FERNÁNDEZ, 1997.

${ }^{3}$ A pesquisa mencionada é resultante de apoio do Programa Jovem Cientista de Nosso Estado RJ/Fundação de Amparo à pesquisa do Estado do Rio de Janeiro e do Programa 
PROCIÊNCIA da Universidade do Estado do Rio de Janeiro, dos quais participa a primeira autora. O estudo também diz respeito ao projeto de Estágio Pós-Doutoral da segunda autora, financiado pela Capes, sob o Processo BEX 10791/13-2.

${ }^{4}$ Para a relação das obras mencionadas ver BITTENCOURT, 2008, p.120. A autora, na seção "Confrontos na produção didática: História Universal ou História da Civilização", apresenta esse debate no que se refere aos livros didáticos do período pesquisado. Ibidem, p.120-133.

${ }^{5}$ Segundo Gasparello, o termo cadeira aproximava-se a uma especialidade dos estudos, próximo ao que hoje denominamos como disciplina. Assim, se em um momento havia a cadeira de História e Geografia, em outros, houve a criação da cadeira de História do Brasil, com um lente especialista, autoridade da cadeira. Naquele momento dizia-se que os lentes regiam cadeiras e os professores (substitutos) davam aulas. Cf. GASPARELLO, 2004, p.69.

${ }^{6}$ Arlette Gasparello mostra como se deu no Brasil a disputa entre o modelo humanista e o modelo moderno e realista no estabelecimento da forma escolar do ensino secundário brasileiro, um dos fatores para as mudanças na definição de aulas destinadas à distribuição das narrativas nacional e universal entre o século XIX e XX. Cf. GASPARELLO, 2004, p.60.

${ }^{7}$ Sobre a reforma Francisco Campos e os intensos debates prévios e dela resultantes, ver REZNIK, 1992.

${ }^{8}$ Ibidem.

'É o conjunto de leis educacionais conhecidas como "Leis Orgânicas do Ensino", que compreendem a estruturação do ensino industrial, a reforma do ensino comercial, a criação do Senai e mudanças no ensino secundário. Cf. ARANHA, 2002.

${ }^{10}$ Trata-se das seguintes coleções: FARIA; MARQUES, 1984; SANTOS, 1992; MOCELLIN, 1997.

${ }^{11}$ Entre as alternativas que surgiram naquele momento está a busca de aplicar à história escolar o modelo de modos de produção. Ainda durante o regime militar surge a obra História das Sociedades, que em seus diversos volumes apresenta como subtítulos os modos de produção predominantes na história humana. Esses livros mantinham a separação entre a história do Brasil e a do mundo. V. AQUINO, 1980.

${ }^{12}$ Um exemplo amplamente estudado no campo do Ensino de História é a experiência da Coordenadoria de Estudos e Normas Pedagógicas (Cenp-SP), com assessoria dos professores Déa Fenelon (PUCSP) e Marcos Silva (USP), que deu origem a uma importante revisão curricular entre os anos de 1984 e 1986 no estado de São Paulo. Para aprofundar o assunto ver FONSECA, 1993.

${ }^{13}$ O Guia de Livros Didáticos dessa edição do PNLD apresentou a aprovação das coleções por série, uma vez que o Edital previa a possibilidade de avaliar separadamente os volumes, aprovando uns e excluindo outros. Assim, os dados ora apresentados são relativos aos livros aprovados para a $5^{\mathrm{a}}$ série, volume 1 . 
${ }^{14}$ Reconhecendo a distinção entre as denominações de História Mundial ou História Global, entendemos que o fenômeno na história escolar se qualifica mais adequadamente como história mundial. A especificidade de cada uma dessas denominações e suas propostas pode ser acessada em MASLISH, 1998.

${ }^{15}$ A respeito da reflexão historiográfica acerca da história global e da história mundial, ver IGGERS, 2008. A apresentação e crítica de alternativas para uma macro-história é feita por WEINSTEIN, 2003. A crítica ao presentismo das propostas citadas está em HARTOG, 2013.

${ }^{16}$ As autoras decidiram não nomear cada coleção e sim referir-se a elas por números, evitando, assim, sua identificação.

${ }^{17}$ Discussão empreendida por GRUZINSKI, 2003.

Artigo recebido em 7 de julho de 2014. Aprovado em 15 de outubro de 2014. 